\title{
Determinants of Mild Clinical Symptoms in Cystic Fibrosis Patients Residual Chloride Secretion Measured in Rectal Biopsies in Relation to the Genotype
}

Henk J. Veeze, * Dicky J. J. Halley, ${ }^{\ddagger}$ Jan Bijman, Johan C. de Jongste, “ Hugo R. de Jonge," and Maarten Sinaasappel * Departments of *Pediatrics and ${ }^{\ddagger}$ Clinical Genetics, Erasmus University and University Hospital/Sophia Children's Hospital; and Departments of ${ }^{\S}$ Cell Biology and "Biochemistry, Erasmus University, 3015 GJ Rotterdam, The Netherlands

\begin{abstract}
Previous Ussing chamber measurements of secretagogue-provoked changes in short circuit current in rectal suction biopsies of cystic fibrosis (CF) patients showed that in a minority of patients chloride secretion in response to cholinergic agonists is reduced but not completely absent. To assess a possible relationship between this phenomenon and both the genotype and the phenotype, we performed Ussing chamber experiments on rectal suction biopsies of 51 CF patients. The CF mutation was identified in 89 out of 102 CF alleles. No apparent chloride secretion was found in $\mathbf{3 0}$ CF patients (group I). Low residual chloride secretion was found in 11 CF patients (group II), while a relatively high residual secretion appeared in $10 \mathrm{CF}$ patients (group III). Pancreatic function was preserved more frequently in CF patients displaying residual secretion: $0 \%$ in group I, 27\% in group II, and 60\% in group III $(P<0.001)$. The age at diagnosis (mean \pm SEM) in group III $(18.4 \pm 6.6)$ was significantly different from group I $(1.2 \pm 0.4, P<0.01)$ and group II (3.5 $\pm 1.4, P=0.05)$. Residual chloride secretion was found in some of the $28 \mathrm{dF508}$ homozygous patients (three in group II, and one in group III), disclosing that other factors than the CF gene defect itself affect the transepithelial chloride transport. The age at diagnosis correlates significantly with the magnitude of the secretory response, even within the dF508 homozygous patients $(r=0.4, P<0.05)$. We conclude that residual chloride secretion in $\mathrm{CF}$ is the pathophysiological basis of preserved pancreatic function and delayed presentation of the disease, which is not exclusively determined by the CF genotype. (J. Clin. Invest. 1994. 93:461-466.) Key words: cystic fibrosis • intestinal secretion • genotype • phenotype • mutational analysis
\end{abstract}

\section{Introduction}

In cystic fibrosis $(\mathrm{CF})^{1}$ conductive chloride transport is defective in epithelial tissues. This results in viscous secretions asso-

Address correspondence to Dr. H. J. Veeze, Sophia Children's Hospital, Dr. Molewaterplein 60, 3015 GJ Rotterdam, The Netherlands.

Received for publication 26 March 1993 and in revised form 5 October 1993.

1. Abbreviations used in this paper: CF, cystic fibrosis; CFTR, cystic fibrosis transmembrane regulator; DIOS, distal intestinal obstruction syndrome; FVC, forced vital capacity; FEV1, forced expiratory volume in $1 \mathrm{~s}$; $\mathrm{I}_{\mathrm{SC}}$, short circuit current; $\mathrm{M}$, mucosal bath; $\mathrm{S}$, serosal bath.

J. Clin. Invest.

(C) The American Society for Clinical Investigation, Inc.

$0021-9738 / 94 / 02 / 0461 / 06 \$ 2.00$

Volume 93, February 1994, 461-466 ciated with pulmonary infections, malabsorption, and intestinal obstruction (1-3). A major gene defect (dF508) represents $\sim 70 \%$ of the gene mutations in $\mathrm{CF}(4,5)$. The product of the CF gene, the cystic fibrosis transmembrane conductance regulator (CFTR), functions itself as a chloride channel and may therefore be held responsible for the known defect in transepithelial chloride transport in $\mathrm{CF}(6,7)$. In most $\mathrm{CF}$ patients, including dF508, the mutation in the CF gene results in a mislocalization rather than dysfunctioning of the CFTR-chloride channel (8-13). In a smaller group of CF patients, however, the channel protein is properly inserted into the apical membrane of the epithelial cells but is functionally impaired or inactive $(8,14)$.

The severity of the disease ranges widely. Homozygosity for the dF508 mutation was found to correlate with pancreatic insufficiency (15-18), early diagnosis (16-19), poor lung function $(16,18)$, chronic pseudomonas colonization (18), and high mortality (18). A relationship between clinical manifestations of the disease and the genotype implies that abnormalities in transepithelial electrolyte transport may vary with specific mutations. More than 230 different CF mutations have now been described (20).

In contrast to other epithelia of CF patients, intestinal tissues not only show defective chloride secretion in response to cAMP-linked secretagogues, but also in response to Ca-linked secretagogues, including cholinergic stimulation (21-23). As shown by electrophysiological studies in isolated colonic crypts (24) and in colonic epithelial cell lines $(25,26)$, a major stimulating effect of carbachol is on the basolateral potassium conductance, creating an increased driving force for chloride exit through CFTR-chloride channels in the apical membrane (24, 25 ). Furthermore, the protein kinase $C$ component of the carbachol response may activate the CFTR-chloride channel by direct phosphorylation (27-29). However, in contrast to their prominent role in other epithelial tissues in the intestine, the contribution of calcium-activated chloride channels (different from CFTR) to the apical chloride secretion is negligible (26, 30, 31 ).

Recently, we demonstrated that in a minority of CF patients chloride secretion provoked by cholinergic agonists was reduced but not completely absent (32). This residual transepithelial chloride transport could help to explain the clinical heterogeneity among $C F$ patients $(32,33)$. To assess a possible relationship between this phenomenon and both the genotype and the phenotype, we extended our Ussing chamber experiments on rectal suction biopsies to a larger group of CF patients and found a relationship between residual chloride secretion and both a milder phenotype and the CF genotype.

\section{Methods}

Patients. This study was approved by the Hospital Medical Ethical Committee and by patients or their parents by written informed con- 
sent. During the study period of $2 \mathrm{yr}, 173$ pediatric and adult CF patients ( 78 male, 95 female) with a mean age of $14.8 \mathrm{yr}$ (range, 0.1-69.9 yr) who regularly visited our University Hospital were asked to have a rectal suction biopsy taken. Supplemented with 2 patients homozygous for the G542X mutation who came from another clinic, a total of 51 CF patients ( 25 male, 26 female) with a mean age of $16.5 \mathrm{yr}$ (range, 0.1-69.9 yr) were enrolled in the study. Each patient's diagnosis was confirmed by at least two abnormal sweat tests ( $>70 \mathrm{mmol}$ sodium/ liter or $>60 \mathrm{mmol}$ chloride/liter).

The medical records were evaluated for a history of meconium ileus, pancreatic insufficiency, distal intestinal obstruction syndrome (DIOS), chronic pseudomonas colonization, and nasal polyp extraction. Pancreatic sufficiency was defined as normal fecal chymotrypsin $(>6.3 \mathrm{U} / \mathrm{g})$ and fat content values $(<5 \mathrm{~g} / \mathrm{d})$ without pancreatic enzyme supplements. The date of onset of chronic pseudomonas colonization was defined as the date of the first isolation of at least two consecutive sputum samples from which pseudomonas could be cultured. Records of forced vital capacity (FVC) and forced expiratory volume in $1 \mathrm{~s}$ (FEV1) were measured and expressed as a percentage of predicted normal values for age, height, and sex. The results of each patient's most recent pulmonary function tests were used. At the end of the 2-yr study period, each subject was assigned a clinical score with the use of the Shwachman and Kulczycki clinical scoring system as modified by Doershuk et al. (34). This is based on general activity, pulmonary physical findings, growth and nutrition, and $\mathrm{x}$-ray findings, resulting in a score from 20 (worst) to 100 (best). Furthermore, each patient's age at diagnosis and maximal derived (current age at the end of the 2-yr study period or age at death) were recorded. Four patients died during the study period.

Electrophysiological study. The procedure of short circuit current $\left(\mathrm{I}_{\mathrm{sC}}\right)$ measurements on rectal tissue has been described earlier (32). Briefly, fresh rectal suction biopsies were mounted in an Ussing chamber with an exposed area of $1.13 \mathrm{~mm}^{2}$. After stabilization of the basal $I_{S C}$, various substances were added to the mucosal $(M)$ and/or serosal (S) baths: ( $a$ ) glucose ( $10^{-2} \mathrm{~mol} /$ liter) was added to $\mathrm{M}$ and S; (b) to reduce the contribution of electrogenic sodium absorption to the $\mathrm{I}_{\mathrm{sC}}$, specific sodium channels were blocked by amiloride $\left(10^{-4} \mathrm{~mol} /\right.$ liter) added to $\mathbf{M} ;(c)$ the endogenous prostaglandin synthesis that is possibly linked to cAMP-mediated chloride secretion was inhibited by adding indomethacin ( $\left.10^{-5} \mathrm{~mol} / \mathrm{liter}\right)$ to $\mathrm{M}$ and $\mathrm{S} ;(d)$ by adding carbachol $\left(10^{-4} \mathrm{~mol} /\right.$ liter $)$ to $S$ the cholinergic activation of chloride secretion was initiated. All chemicals were obtained from Sigma Chemical Co. (St. Louis, MO).

To investigate the reproducibility of the experiments without increasing discomfort for the participants, we analyzed two biopsy specimens simultaneously in a subgroup of $18 \mathrm{CF}$ patients.

The mean carbachol-provoked change in $\mathrm{I}_{\mathrm{SC}}$ values $( \pm \mathrm{SEM})$ was $35.1 \pm 2.6 \mu \mathrm{A} / \mathrm{cm}^{2}$ in 47 healthy volunteers $<18 \mathrm{yr}$ old, and $22.4 \pm 4.3$ $\mu \mathrm{A} / \mathrm{cm}^{2}$ in 8 subjects $>18 \mathrm{yr}$ old. This difference tended to be statistically significant $(P=0.07$, Mann-Whitney; Pearson's correlation between age and $\left.\mathrm{I}_{\mathrm{sc}}: r=-0.23, P=0.10\right)$. The inward current provoked by carbachol in controls ( $I_{\text {sc }}$ positive; Fig. 1 ) reflects transcellular chloride transport (serosa to mucosa) through the $\mathrm{Na}-\mathrm{K}-\mathrm{Cl}$ cotransporter in the basolateral membrane and the CFTR-chloride channel in the apical membrane (32). The observed magnitude of this response in controls may well be underestimated by underlying potassium secretion (32).

In the majority of CF patients, hereafter classified as group I, carbachol induces only an outward current response ( $I_{\text {sc }}$ negative; Fig. 1). Most plausibly this reversed current results from apical potassium secretion that is unmasked in the case of absent or largely reduced chloride secretion $(32,35,36)$. The carbachol-provoked $I_{S C}$ changes in $C F$ patients, and possibly also in controls, may therefore be the net result of two opposite currents. In a subclass of CF patients, usually after a negative peak response, a separate and small positive peak response (i.e., inward current) was observed (Fig. 1, groups II and III). To facilitate comparison with the data from group I and controls, the net maximal change in $I_{\mathrm{sc}}$ was defined as the sum of the negative and positive peak responses (Fig. 1, neg + pos). This calculated response was either negative (low residual secretion, group II) or positive (high residual secretion, group III).

DNA analysis. We analyzed for the R117H, R347P, A455E, 621 $+1 \mathrm{G} \rightarrow \mathrm{T}, \mathrm{dl} 507, \mathrm{dF} 508,1717-1 \mathrm{G} \rightarrow \mathrm{A}, \mathrm{V} 520 \mathrm{~F}, \mathrm{G} 542 \mathrm{X}, \mathrm{S} 549 \mathrm{~N}$, S5491, G551D, R553X, R1162X, S1251N, W1282X, and N1303K mutations by PCR amplification of the appropriate exon sequences. Specific mutation detection involved the use of allele-specific oligonucleotides or amplification refractory mutation system (ARMS) $(5,37$, 38 ). In addition, PCR-amplified exons 10 and 11 , which are known to contain several mutations, were subjected to single strand conformation polymorphism as an aspecific screen for sequence alterations in these exons (39).

Statistics. Differences were considered significant if $P \leq 0.05$. The Pearson's correlation coefficient was calculated between short circuit current and age at diagnosis. Comparing the maximal derived age, a survival analysis was performed using the log-rank test for testing significancy. All statistical tests were two tailed.

\section{Results}

The reduction in basal $I_{S C}$ in response to amiloride (mean \pm SEM) in CF patients $\left(-9.2 \pm 1.6 \mu \mathrm{A} / \mathrm{cm}^{2} ; n=51\right.$ ) was not different from age-matched control values $(-8.7 \pm 1.5 \mu \mathrm{A} /$ $\mathrm{cm}^{2} ; n=50$ ). This outcome strengthens our previous conclusion that the strong increase in apical sodium channel activity seen in CF airway does not occur in rectal epithelium (32).

Three groups of CF patients could be distinguished on the basis of the electrophysiological response to carbachol. Group I consisted of 30 patients who failed to demonstrate residual intestinal chloride secretion. In group II, 11 patients showed low residual chloride secretion, and group III consisted of 10 patients displaying high residual chloride secretion. From group I to III, the CF patients had a milder clinical presentation of the disease. This is demonstrated by the age at diagnosis, which is significantly higher in CF patients with high residual secretion compared with groups I and II ( Table I). The difference in the age at diagnosis between groups I and II indicates that even $\mathrm{CF}$ patients with a low residual secretion are less affected by the

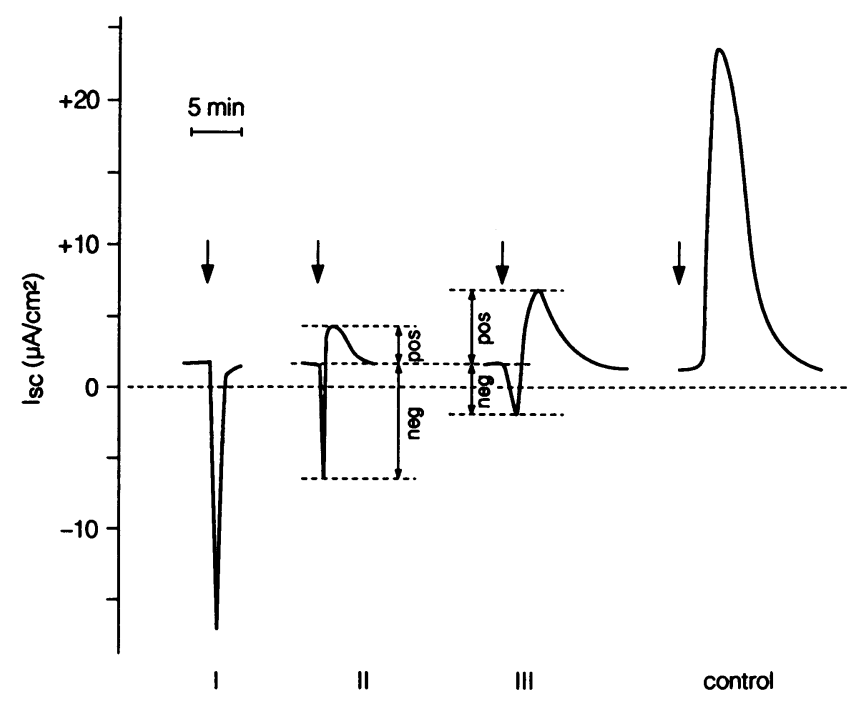

Figure 1. Different patterns of carbachol-induced $I_{S C}$ responses in rectal epithelium in the presence of amiloride and indomethacin. Additions are marked by arrows. For concentrations and site of additions, see Methods. 
Table I. Characteristics of CF Patients with a Different Pattern of Carbachol-induced Changes in $I_{s c}$ in Rectal Suction Biopsies in the Presence of Amiloride and Indomethacin

\begin{tabular}{|c|c|c|c|}
\hline & \multicolumn{3}{|c|}{ Intestinal chloride secretion } \\
\hline & $\begin{array}{l}\text { I: No apparent } \\
\text { residual secretion }\end{array}$ & $\begin{array}{l}\text { II: Low residual } \\
\text { secretion }\end{array}$ & $\begin{array}{l}\text { III: High residual } \\
\text { secretion }\end{array}$ \\
\hline CF patients $(n)$ & 30 & 11 & 10 \\
\hline \multicolumn{4}{|l|}{ Carbachol induced secretion: } \\
\hline Net change in $I_{s c}\left(\mu \mathrm{A} / \mathrm{cm}^{2}\right)$ & $-8.8 \pm 2.1$ & $-5.8 \pm 1.5$ & $5.2 \pm 1.4^{*}$ \\
\hline \multicolumn{4}{|l|}{ Genotype: } \\
\hline 1. dF508/N1303K & 2 & 0 & 0 \\
\hline 2. dF508/dF508 & 24 & 3 & 1 \\
\hline 3. $\mathrm{dF} 508 / \mathrm{G} 542 \mathrm{X}$ & 1 & 1 & 0 \\
\hline 4. G542X/G542X & 0 & 2 & 0 \\
\hline 5. dF508/A455E & 0 & 1 & 3 \\
\hline 6. A455E/other & 0 & 0 & 1 \\
\hline 7. R553X/other & 0 & 1 & 0 \\
\hline 8. dF508/other & 3 & 3 & 5 \\
\hline Age at diagnosis (yr) & $1.2 \pm 0.4$ & $3.5 \pm 1.4$ & $18.4 \pm 6.6^{\ddagger}$ \\
\hline Died in study period $(n)$ & 2 & 2 & 0 \\
\hline Maximal derived age (yr) & $14.3 \pm 2.0$ & $13.0 \pm 2.4$ & $26.9 \pm 6.4^{\S}$ \\
\hline Shwachman score & $69.0 \pm 4.2$ & $74.1 \pm 7.6$ & $74.0 \pm 7.0$ \\
\hline \multicolumn{4}{|l|}{ Pulmonary function: } \\
\hline CF patients $(n)$ & 19 & 8 & 7 \\
\hline Age (yr) & $19.1 \pm 1.7$ & $15.4 \pm 1.4$ & $33.9 \pm 6.8$ \\
\hline FVC (\% predicted) & $68.1 \pm 4.2$ & $75.4 \pm 10.3$ & $81.8 \pm 7.3$ \\
\hline FEV1 (\% predicted) & $51.9 \pm 5.4$ & $63.9 \pm 12.4$ & $58.5 \pm 10.7$ \\
\hline Pancreatic insufficiency $(n[\%])$ & $30[100]$ & $8[73]$ & $4[40]^{\prime \prime}$ \\
\hline Meconium ileus ( $n[\%])$ & $10[33]$ & $2[18]$ & $1[10]$ \\
\hline $\operatorname{DIOS}(2 \mathrm{n}[\%])$ & $4[14]$ & $0[0]$ & $0[0]$ \\
\hline Pseudomonas colonization ( $n[\%]$ ) & $21[72]$ & $7[64]$ & $4[40]$ \\
\hline Nasal polyp extraction ( $n[\%])$ & $9[31]$ & $1[9]$ & $3[30]$ \\
\hline
\end{tabular}

Values are expressed as mean \pm SEM unless otherwise indicated. Differences of group III from groups I or II: *I, II: $P<0.001 ;{ }^{\ddagger} \mathrm{I}: P<0.01$, II: $P$ $=0.05$, Mann-Whitney; ${ }^{\S} \mathrm{I}: P<0.05$, II: $P=0.06$, log-rank test; " $P<0.001$, Fisher's exact test.

disease $(P=0.07$, Mann-Whitney) than those without. The proportion of pancreatic insufficient CF patients decreases significantly from groups I to III (Table I). Additionally, the mean carbachol-provoked $\mathrm{I}_{\mathrm{SC}}$ response in the 9 pancreatic sufficient patients ( 3 of group II and 6 of group III) was significantly higher $\left(2.6 \pm 2.5 \mu \mathrm{A} / \mathrm{cm}^{2}\right)$ than in the other 42 pancreatic insufficient patients $\left(-7.1 \pm 1.6 \mu \mathrm{A} / \mathrm{cm}^{2} ; P<0.01\right.$, MannWhitney). The proportion of CF patients with other intestinal symptoms (meconium ileus and DIOS) was also lower in group III, but the differences were not significant (Table I). The prevalences of pseudomonas colonization, and nasal polyp extraction are summarized in Table I. Comparing the lung functions and Shwachman scores ( Table I), as well as the previously mentioned prevalence of pancreatic status, DIOS, pseudomonas colonization, and nasal polyp extraction, we have to take into account that the time for CF patients of group III to develop more advanced disease was longer. This is demonstrated by their average maximal derived age, which was significantly higher in group III than in the other groups (Table I).

The distribution of genotypes among the three groups defined on the basis of electrophysiological response is indicated in Table I. Of all genotypes the dF508 homozygous patients are most frequent ( $55 \%$ ). Most, but not all, of them lack a positive $\mathrm{I}_{\mathrm{SC}}$ component in their response ( Table I). CF patients carrying one A455E mutation are predominantly found in group III. Considering the variability in $\mathrm{I}_{\mathrm{SC}}$ responses, even within the dF508 homozygous patient group, we also asked ourselves whether or not a relationship existed between the magnitude of the secretory response and the phenotypic expression of the disease. A positive correlation $(r=0.37, P<0.01)$ was found between age at diagnosis and the net $\mathrm{I}_{\mathrm{SC}}$ response (Fig. 2). This correlation was also significant $(r=0.40, P<0.05)$ for the dF508 homozygous patients.

Two CF patients combined dF508 with G542X; one of these showed low residual secretory activity. The two CF patients homozygous for the G542X mutation both displayed low residual secretion (Table I). All CF patients with one A455E allele showed residual activity (Table I). Compared with all other genotypes in this study, these CF patients are diagnosed at a significantly older age, have a higher $\mathrm{I}_{\mathrm{sc}}$ response, have a higher maximal derived age, and are less frequently pancreatic insufficient (Table II).

In $18 \mathrm{CF}$ patients duplicate rectal suction biopsies were studied. When every first result (Fig. $2, x$-axis) equals the results of the duplicate registration ( $y$-axis), then a line through zero $(\beta=$ intercept $=0)$ with a tangent $=1$ can be drawn. In the equation: Result $1=\alpha$ Result $2+\beta$, the $\beta$ was -1.5 (not different from 0 ) and the $\alpha$ was 0.7 (not different from 1). 


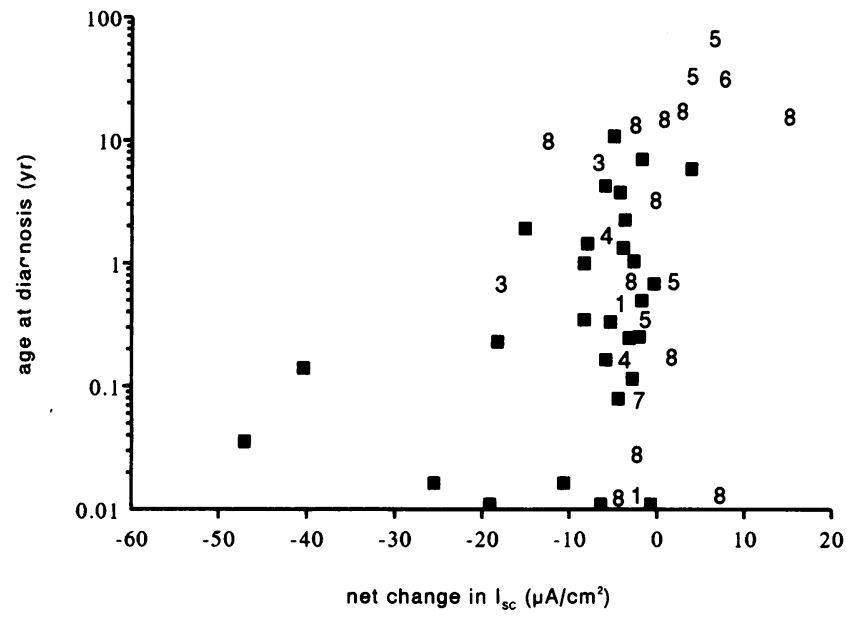

Figure 2. Correlation between age at diagnosis and $\mathrm{I}_{\mathrm{SC}}$ measurements on rectal suction biopsies of CF patients $(r=0.37, P<0.01)$. The correlation was also found in the dF508 homozygous patients $(\square)(r$ $=0.40, P<0.05$ ). The other genotypes, indicated by numbers, are explained in Table I. Positive net $\mathrm{I}_{\mathbf{S C}}$ changes implicate net residual chloride secretion while a negative response indicates predominant $\mathrm{K}^{+}$secretion perhaps blunted by underlying residual $\mathrm{Cl}^{-}$secretion.

\section{Discussion}

The changes in $\mathrm{I}_{\mathrm{SC}}$ provoked by carbachol represent the net result of all electrical charge fluxes through both apical and basolateral membranes. A positive change in $I_{S C}$ induced by carbachol in a control biopsy specimen is an indicator for net electrogenic chloride secretion. However, in most CF patients, responses to carbachol are characterized by a change in $\mathrm{I}_{\mathrm{SC}}$ in

Table II. Characteristics of CF Patients with One A455E Mutation vs. All Other Tested Mutants

\begin{tabular}{lcc}
\hline & \multicolumn{2}{c}{ Genotype } \\
\cline { 2 - 3 } & $\begin{array}{c}1,2,3,4,7,8 \\
\text { (see Table I) }\end{array}$ & $\begin{array}{c}5 \text { (dF508/A455E) } \\
5 \text { (A455E/other) }\end{array}$ \\
\hline Patients $(n)$ & 46 & 5 \\
Carbachol induced secretion: & & \\
$\quad$ Net change in $\mathrm{I}_{\text {sc }}\left(\mu \mathrm{A} / \mathrm{cm}^{2}\right)$ & $-6.4 \pm 1.6$ & $3.8 \pm 1.7^{*}$ \\
Age at diagnosis (yr) & $2.7 \pm 0.7$ & $26.3 \pm 12.4^{\ddagger}$ \\
Died in study period & 4 & 0 \\
Maximal derived age (yr) & $14.5 \pm 1.5$ & $35.0 \pm 11.4^{\S}$ \\
Shwachman score & $67.0 \pm 12.5$ & $71.5 \pm 3.4$ \\
Pulmonary function: & & \\
CF patients $(n)$ & 30 & 4 \\
Age (yr) & $18.4 \pm 1.2$ & $42.9 \pm 9.8$ \\
FVC (\% predicted) & $72.7 \pm 4.1$ & $72.5 \pm 8.0$ \\
FEV1 (\% predicted) & $57.9 \pm 5.1$ & $42.1 \pm 7.4$ \\
Pancreatic insufficiency $(n[\%])$ & $41[89]$ & $1[20]^{\| \prime}$ \\
Meconium ileus $(n$ [\%]) & $13[28]$ & $0[0]$ \\
DIOS ( $n$ [\%]) & $4[9]$ & $0[0]$ \\
Pseudomonas colonization $(n[\%])$ & $29[64]$ & $3[60]$ \\
Nasal polyp extraction $(n[\%])$ & $11[24]$ & $2[40]$ \\
& & \\
\hline
\end{tabular}

Values are expressed as mean \pm SEM unless otherwise indicated.

${ }^{*} P<0.01,{ }^{\ddagger} P<0.05$, Mann-Whitney; ${ }^{\S} P<0.001$, log-rank test;

" $P<0.01$, Fisher's exact test. the opposite direction (32). Apparently, this inversed response reflects potassium secretion through apical potassium channels, most likely unmasked by the chloride channel defect associated with the CF condition (32). In both normal and CF tissue the magnitude of the chloride and potassium current, respectively, may well be underestimated when apical potassium channels are also functioning in normal tissue (36) and if apical chloride channels retain a residual activity in CF cells. However, the relative magnitude of chloride and potassium currents for each biopsy is difficult to estimate. First, the small size of the biopsy as well as the transient character of the changes in $\mathrm{I}_{\mathrm{SC}}$ provoked by carbachol prevent accurate assessment of unidirectional ${ }^{36} \mathrm{Cl}$ or ${ }^{86} \mathrm{Rb}$ flux rates. Also, specific inhibitors of apical chloride channels (i.e., CFTR) or apical potassium channels are not yet available (31). The positive $\mathrm{I}_{\mathrm{SC}}$ responses remain representative for residual chloride secretion while negative $\mathrm{I}_{\mathrm{SC}}$ responses indicate predominant potassium secretion, perhaps blunted by underlying residual chloride secretion.

Considering the recent finding that most mutant CFTR is functionally active but is inappropriately targeted to the plasma membrane (8-13), one possible reason for a variable level of residual chloride secretion, in particular among patients of identical genotype, may be a variable degree of mislocation of the CFTR protein in the enterocytes. Alternatively, the variability may arise from a variable expression level of other chloride channel species in the apical membrane, e.g., calcium-activated chloride channels, which normally do not contribute much to the carbachol-provoked changes in $\mathrm{I}_{\mathrm{SC}}$ in intestine $(26,30,31)$. Furthermore, several missense mutations located in the transmembrane domain of CFTR are characterized by an incomplete loss of chloride channel function and may also lead to residual chloride secretion (14).

In Table I, we demonstrate a relationship between residual chloride secretion and clinical parameters. The positive $\mathrm{I}_{\mathrm{SC}}$ responses observed in group III CF patients are not the result of the more advanced mean age in this group, since control values normally decline with increasing age (see Methods). The high residual secretion found in these CF patients might very well be the pathophysiological basis of their milder clinical presentation, as indicated by the age at diagnosis and the preserved pancreatic function. The data from from Table I additionally indicate that, in comparison with groups I and II, and in contrast of what could be expected from their higher current age, CF patients of group III also reach a higher Shwachman score and have a more preserved lung function. The preserved pulmonary function in group III suggests that residual chloride secretion may also occur in airway epithelium. Some of the CF patients (Fig. 2) have a calculated response approaching agematched control values. However, the appearance of their responses was abnormal, due to the (preceding) transient deflection of the $I_{S C}$ that was never observed in controls.

A more continuous relationship between the $I_{S C}$ and the age at diagnosis is illustrated in Fig. 2. Even within the group of dF508 homozygous patients, a positive correlation between the net $\mathrm{I}_{\mathrm{SC}}$ response and the age at diagnosis was found. As discussed above, the variability in phenotypic expression of the disease within patients of identical CF genotype can be explained by interindividual differences in the extent of missorting of mutant CFTR or in the expression of other (compensatory) chloride channels. It has been suggested before that genetic factors other than the CF gene may modify the expression 
of the disease (17). Prediction of the clinical prognosis in individual $C F$ patients may thus not rely on the CF genotype alone.

The previously described genotype-phenotype relationship (16-19) implies that the (residual) function of CFTR may vary with different mutations. In Xenopus oocytes it was demonstrated that the chloride conductance depends on the $\mathrm{CF}$ genotype (9). In this study we demonstrate that most, but not all, dF508 homozygous patients are found in group I and that CF patients with one $\mathrm{A} 455 \mathrm{E}$ mutation can be found predominantly in group III. The latter mutation presumably affects the sorting and/or activity of CFTR to a lesser extent, thus allowing for residual secretion and milder clinical symptoms (Table II). The A455E mutation was also characterized by others as a mild mutation associated with preserved pancreatic function (40). The two dF508/N1303K patients both had pancreatic insufficiency and failed to show apparent residual chloride secretion. This is in agreement with others who characterized the N1303K mutation as a severe one (41).

Interestingly, two patients homozygous for the nonsense mutation G542X had a low residual secretion (in duplicate). Since in other stop codon mutants no CFTR mRNA was detectable (42), the residual chloride secretion in the two homozygous G542X patients most likely results from compensatory non-CF-affected chloride channel species (26) in the apical membrane, rather than from the presence of some functional CFTR.

We conclude that the residual chloride secretion in $\mathrm{CF}$ is the pathophysiological basis of preserved pancreatic function and delayed presentation of the disease. Compared with $\mathrm{dF} 508$, the A455E mutation can be characterized as a mild mutation allowing for residual chloride secretion. The occurrence of residual chloride secretion in the intestine is not exclusively determined by the CF genotype.

\section{Acknowledgments}

We thank J. W. Mouton, S. E. Overbeek, and J. Bouquet, for their collaboration, J. J. Cassiman (Leuven) and A. T. Buikema (Amsterdam) for their help in investigating the G542X/G542X patients, and all the patients for their cooperation in this study. We are indebted to Prof. M. F. Desjeux (Paris) for offering the basic design of the micro Ussing chamber.

This work was supported by the Dutch Liver Gut Foundation.

\section{References}

1. Knowles, M. R., M. J. Stutts, A. Spock, N. Fischer, J. T. Gatzy, and R. C. Boucher. 1983. Abnormal ion permeation through cystic fibrosis respiratory epithelium. Science (Wash. DC). 221:1067-1070.

2. Welsh, M. J., and C. M. Liedtke. 1986. Chloride and potassium channels in cystic fibrosis airway epithelia. Nature (Lond.). 322:467-470.

3. Frizzell, R. A., G. Rechkemmer, and R. L. Shoemaker. 1986. Altered regulation of airway epithelial cell chloride channels in cystic fibrosis. Science (Wash. DC). 233:558-560.

4. Riordan, J. R., J. M. Rommens, B. S. Kerem, N. Alon, R. Rozmahel, Z. Grzelczak, S. Lok, N. Plavsic, J. L. Chou, M. L. Drumm, M. C. Iannuzzi, F. S. Collins, and L. C. Tsui. 1989. Identification of the cystic fibrosis gene: Cloning and characterization of complementary DNA. Science (Wash. DC). 245:10661073.

5. Kerem, B. S., J. M. Rommens, J. A. Buchanan, D. Markiewicz, T. K. Cox, A. Chakravarti, M. Buchwald, and L. C. Tsui L. C. 1989. Identification of the cystic fibrosis gene: Genetic analysis. Science (Wash. DC). 245:1073-1080.

6. Anderson, M. P., R. J. Gregory, S. Thomson, D. W. Souza, S. Paul, R. C. Mulligan, A. E. Smith, and M. J. Welsh. 1991. Demonstration that CFTR is a chloride channel by alteration of its anion selectivity. Science (Wash. DC). 253:202-205.
7. Bear, C. E., C. Li, N. Kartner, R. J. Bridges, T. J. Jensen, M. Ramjeesingh, and J. R. Riordan. 1992. Purification and functional reconstitution of the cystic fibrosis transmembrane conductance regulator (CFTR). Cell. 68:809-818.

8. Cheng, S. H., R. J. Gregory, J. Marshall, S. Paul, D. W. Souza, G. A. White, C. R. O'Riordan C. R, and A. E. Smith. 1990. Defective intracellular transport and processing of CFTR is the molecular basis of most cystic fibrosis. Cell. 63:827-834.

9. Drumm, M. L., D. J. Wilkinson, L. S. Smit, R. T. Worrell, T. V. Strong, R. A. Frizzell, D. C. Dawson, and F. S. Collins. 1991. Chloride conductance expressed by delta F508 and other mutant CFTRs in Xenopus oocytes. Science (Wash. DC). 254:1797-1799.

10. Kartner, N., O. Augustinas, T. J. Jensen, A. L. Naismith, and J. R. Riordan. 1992. Mislocalization of delta F508 CFTR in cystic fibrosis sweat gland. Nature Genetics. 1:321-327.

11. Denning, G. M., M. P. Anderson, J. F. Amara, J. Marshall, A. E. Smith, and M. J. Welsh. 1992. Processing of mutant cystic fibrosis transmembrane conductance regulator is temperature-sensitive. Nature (Lond.). 358:761-764.

12. Puchelle, E., D. Gaillard, D. Ploton, J. Hinnrasky, C. Fuchey, M. C. Boutterin, J. Jacquot, D. Dreyer, A. Pavirani, and W. Dalemans. 1992. Differential localization of the cystic fibrosis transmembrane conductance regulator in normal and cystic fibrosis airway epithelium. Am. J. Respir. Cell Mol. Biol. 7:485-491.

13. Li, C. H., M. Ramjeesingh, E. Reyes, T. Jensen, X. B. Chang, J. M. Rommens, and C. E. Bear. 1993. The cystic fibrosis mutation (delta-F508) does not influence the chloride channel activity of CFTR. Nature Genetics. 3:311-316.

14. Sheppard, D. N., D. P. Rich, L. S. Ostedgaard, R. J. Gregory, A. E. Smith, and M. J. Welsh. 1993. Mutations in CFTR associated with mild-disease-form $\mathrm{Cl}^{-}$channels with altered pore properties. Nature (Lond.). 362:160-164.

15. Santis, G., L. Osborne, R. A. Knight, and M. E. Hodson. 1990. Linked marker haplotypes and the dF508 mutation in adults with mild pulmonary disease and cystic fibrosis. Lancet. 335:1426-1429.

16. Kerem, E., M. Corey, B. S. Kerem, J. M. Rommens, D. Markiewicz, H. Levison, L. C. Tsui, and P. Durie. 1990. The relation between genotype and phenotype in cystic fibrosis analysis of the most common mutation (dF508). N. Engl. J. Med. 323:1517-1522.

17. Santis, G., L. Osborne, R. A. Knight, and M. E. Hodson. 1990. Independent genetic determinants of pancreatic and pulmonary status in cystic fibrosis. Lancet. 336:1081-1084.

18. Johansen, H. K., M. Nir, N. Høiby, C. Koch, and M. Schwartz. 1991. Severity of cystic fibrosis in patients homozygous and heterozygous for the dF508 mutation. Lancet. 337:631-634.

19. Halley, D. J. J., H. J. Veeze, L. A. Sandkuyl, E. Wesby-van Swaay, N. H. M. van Damme, W. H. Deelen, J. E. Witte, and M. F. Niermeijer. 1990. The mutation deltaF508 on Dutch cystic fibrosis chromosomes: frequency and relation to patients age at diagnosis. Hum. Genet. 85:407-408.

20. Tsui, L. C. 1992. The spectrum of cystic fibrosis mutations. Trends Genet. 8:392-398.

21. Berschneider, H. M., M. R. Knowles, R. G. Azizkan, R. C. Boucher, N. A. Tobey, R. C. Orlando, and D. W. Powell. 1988. Altered intestinal chloride transport in cystic fibrosis. FASEB (Fed. Am. Soc. Exp. Biol.) J. 2:2625-2629.

22. Taylor, C. J., P. S. Baxter, J. Hardcastle, and P. T. Hardcastle. 1988. Failure to induce secretion in jejunal biopsies from children with cystic fibrosis. Gut. 29:957-962.

23. Bijman, J., M. Kansen, A. H. Hoogeveen, B. Scholte, A. van der Kamp, and H. R. de Jonge. 1988. Electrolyte transport in normal and CF epithelia. In Exocrine Secretion. P. Y. D. Wong, and J. A. Young, editors. University Press, Hong Kong. 17-19.

24. Greenwald, L., and B. A. Biagi. 1992. Interaction between carbachol and vasoactive intestinal peptide in cells of isolated colonic crypts. Am. J. Physiol. 262:G940-G944.

25. Dharmsathaphorn, K., and S. J. Pandol. 1986. Mechanism of chloride secretion induced by carbachol in a colonic epithelial cell line. J. Clin. Invest. 77:348-354.

26. Anderson, M. P., and M. J. Welsh. 1991. Calcium and cAMP activate different chloride channels in the apical membrane of normal and cystic fibrosis epithelia. Proc. Natl. Acad. Sci. USA. 88:6003-6007.

27. Tabcharani, J. A., X. B. Chang, J. R. Riordan, and J. W. Hanrahan. 1991. Posphorylation-regulated $\mathrm{Cl}^{-}$channel in $\mathrm{CHO}$ cells stably expressing the cystic fibrosis gene. Nature (Lond.). 352:628-631.

28. Vaandrager, A. B., N. van den Berghe, A. G. M. Bot, and H. R. de Jonge. 1992. Phorbol esters stimulate and inhibit $\mathrm{Cl}^{-}$secretion by different mechanisms in a colonic cell line. Am. J. Physiol. 262:G249-G256.

29. Berger, H. A., S. M. Travis, and M. J. Welsh. 1993. Regulation of the cystic fibrosis transmembrane conductance regulator $\mathrm{Cl}^{-}$channel by specific protein kinases and protein phosphatases. J. Biol. Chem. 268:2037-2047.

30. Bajnath, R. B., K. Dekker, A. B. Vaandrager, H. R. de Jonge, and J. A. Groot. 1992. Biphasic increase of apical $\mathrm{Cl}^{-}$conductance by muscarinic stimulation of HT-29cl.19A human colon carcinoma cell line: evidence for activation of different $\mathrm{Cl}^{-}$conductances by carbachol and forskolin. J. Membr. Biol. 127:8194. 
31. Vaandrager, A. B., R. Bajnath, J. A. Groot, A. G. M. Bot, and H. R. De Jonge. 1991. $\mathrm{Ca}^{++}$and CAMP activate different chloride efflux pathways in HT29.cl19A colonic epithelial cell line. Am. J. Physiol. 261:G958-G965.

32. Veeze, H. J., M. Sinaasappel, J. Bijman, J. Bouquet, and H. R. de Jonge. 1991. Ion transport abnormalities in rectal suction biopsies from children with cystic fibrosis. Gastroenterology. 101:398-403.

33. Taylor, C. J., H. Hughes, P. T. Hardcastle, and J. Hardcastle. 1992. Genotype and secretory response in cystic fibrosis. Lancet. 339:67-68.

34. Doershuk, C. F., L. W. Matthews, A. S. Tucker, H. Nudelman, G. Eddy, M. Wise, and S. Spector. 1964. A 5 year clinical evaluation of a therapeutic program for patients with cystic fibrosis. J. Pediatr. 65:677-693.

35. Halm, D. R., and R. A. Frizzell. 1986. Active $K$ transport across rabbit distal colon: relation to $\mathrm{Na}$ absorption and $\mathrm{Cl}$ secretion. Am. J. Physiol. 251:C252-67.

36. Goldstein, J. L., A. B. Shapiro, M. C. Rao, and T. J. Layden. 1991. In vivo evidence of altered chloride but not potassium secretion in cystic fibrosis rectal mucosa. Gastroenterology. 101:1012-1019.

37. Halley, D. J. J., N. H. M. Damme, W. H. Deelen, B. A. Oostra, M. G. J. Jahoda, E. S. Sachs, F. J. Los, and M. F. Niermeijer. 1989. Prenatal detection of major cystic fibrosis mutation. Lancet. ii:972.
38. Ferrie, R. M., M. J. Schwarz, N. H. Robertson, S. Vaudin, M. Super, G. Malone, and S. Little. 1992. Development, multiplexing, and amplification of ARMS tests for the common mutations in the CFTR gene. Am. J. Hum. Genet. 51:251-262.

39. Orita, M., Y. Suzuki, Sekiya, T., and K. Hayashi. 1989. Rapid and sensitive detection of point mutations and DNA polymorphisms using the polymerase chain reaction. Genomics. 5:874-879.

40. Kristidis, P., D. Bozon, M. Corey, D. Markiewicz, J. Rommens, L. C. Tsui, and P. Durie. 1992. Genetic Determination of Exocrine Pancreatic Function in Cystic Fibrosis. Am. J. Hum. Genet. 50:1178-1184.

41. Osborne, L., G. Santis, M. Schwarz, K. Klinger, T. Dork, I. Mcintosh, M. Schwartz, V. Nunes, M. Macek, J. Reiss, et al. 1992. Incidence and expression of the N1303K mutation of the cystic fibrosis (CFTR) gene. Hum. Genet. 89:653658.

42. Hamosh, A., B. C. Trapnell, P. L. Zeitlin, C. Montrose-Rafizadeh, B. J. Rosenstein, R. G. Crystal, and G. R. Cutting. 1991. Severe deficiency of cystic fibrosis transmembrane conductance regulator messenger RNA carrying nonsense mutations R553X and W1316X in respiratory epithelial cells of patients with cystic fibrosis. J. Clin. Invest. 88:1880-1885. 